\title{
EFFECTS OF N-METHYLAMINO ACIDS AND CONVULSANTS ON SPONTANEOUS ACTION POTENTIALS IN GUINEA-PIG CEREBELLAR SLICES
}

\author{
K. OKAMOTO' \& J.H. QUASTEL \\ Division of Neurological Sciences, Department of Psychiatry, University of British Columbia,
} Vancouver, B.C., V6T 1W5, Canada

$1 \quad N$-methyl- $\gamma$-aminobutyrate ( $N$-methylGABA), $N$-methylglycine, $N$-methyltaurine and $N$-methyl $\beta$ alanine diminished the frequency of spontaneous spike discharges in guinea-pig cerebellar slices. Usually a weak excitatory effect preceded the inhibition.

2 The inhibitory effects of $N$-methylGABA and $N$-methyl $\beta$-alanine were competitively antagonized by both picrotoxin and strychnine.

3 The inhibitory action of $N$-methyltaurine was competitively suppressed by strychnine and by low concentrations of picrotoxin.

4 The inhibitory action of $N$-methylglycine was suppressed by strychnine but not by picrotoxin. The suppression was competitive at low concentrations of strychnine.

$5 \mathrm{~N}$-methylDL-glutamate brought about a strong inhibition followed by a strong excitation of the neurones. The inhibitory effects were competitively suppressed by both picrotoxin and strychnine. Neither convulsant affected the excitation.

6 Whereas L- or D-glutamate caused only excitation in the majority of cells examined, a small proportion of the cells exhibited inhibition preceding the excitation by L- or D-glutamate. Such inhibitory effects were suppressed by picrotoxin but not by strychnine.

7 Kinetic analyses of the dose-response curves for the $N$-methylamino acid in the presence or absence of the convulsant indicated that the number of molecules of the amino acid combining with the receptor site to produce a response was 3 for $N$-methylGABA, 2 for $N$-methylglycine, 3 for $N$ methyltaurine, 3 for $N$-methyl $\beta$-alanine. The corresponding value was 1 for $N$-methylDL-glutamate (inhibition). The number of molecules of convulsant combining with the receptor site was calculated to be 2 for picrotoxin with $N$-methylGABA, $N$-methyl $\beta$-alanine and $N$-methylDL-glutamate and 1 for strychnine with all $N$-methylamino acids examined.

\section{Introduction}

We have shown in earlier papers (Okamoto \& Quastel, 1973; 1976) that the frequencies of spontaneous action potentials recorded from guineapig cerebellar cortex slices are reversibly suppressed by inhibitory amino acids such as $\gamma$-aminobutyrate (GABA), glycine, taurine and $\beta$-alanine. The inhibitory effect of GABA is competitively antagonized by picrotoxin, whereas that of glycine, taurine and $\beta$-alanine is competitively blocked by strychnine. These results indicate that there seem to exist at least two types of receptors for the inhibitory amino acids in the cerebellar cortex, one specific for picrotoxin and the other specific for strychnine.

1 Present address: Department of Pharmacology, National Defence Medical College, Tokorozawa-City, SaitamaPrefecture, Japan.
The present study was carried out to answer the following question: Do the antagonists, picrotoxin and strychnine, still maintain their specificities of action when the amino acid molecule is modified by $N$ alkylation? $N$-methylamino acids were chosen for the present study for the following reasons: (1) Methylation of the $N$-atom does not necessarily result in loss of the physiological activities of the parent amino acids, even though the amino group is considered to combine with the anionic site of the receptor (Curtis \& Watkins, 1960). Indeed, there may even be a potentiation of the activity on neuronal excitability. $N$-methylDL-aspartate, for example, is reported to be about five times as potent as DLaspartate (Curtis \& Watkins, 1963). Curtis \& Watkins (1960; 1963) and Curtis, Phillis \& Watkins (1961) have also described an excitatory effect of $N$ - 
methylDL-glutamate, which was as potent as that of DL-glutamate, and inhibitory effects of $N$-methyl $\beta$ alanine, $N$-methylglycine and $N$-methylGABA with cat spinal neurones and isolated spinal cord of the toad, though these were weaker than those of the parent non-methylated amino acids. (2) Some $N$ methylamino acids are known to occur naturally. For example, $N$-methylglycine (sarcosine) exists in the mammalian body (Scott \& Labbe, 1974). $N$ methylisoleucine and $N$-methylvaline are present in fungi and $N$-methyltyrosine and $N$-methyltryptophan exist in plants (Guggenheim, 1951). (3) Some $N$ methylamino acids may have physiological importance. For example, the genetic disease, hypersarcosinemia, that is accompanied by neurological disturbance, is associated with the accumulation of $N$ methylglycine in the blood (Scott \& Labbe, 1974). $N$ methyl $\beta$-alanine competitively inhibits the active transport of GABA and $\beta$-alanine in cerebral cortex slices, indicating its ability to bind with transport carrier site(s) on neuronal membranes (Johnston \& Stephanson, 1976). (4) $N$-methylation of an amine (tryptamine) has been shown to occur with a brain preparation (Boarder, Oon \& Rodnight, 1976). It seems possible therefore that $N$-methylation of an amino acid may take place in the brain.

We have found that $N$-methylGABA, $N$ methylglycine, $N$-methyltaurine and $N$-methyl $\beta$ alanine have inhibitory effects similar to those shown by their non-methylated parent amino acids, on the frequencies of spike discharges in guinea-pig cerebellar slices. $N$-methylDL-glutamate exhibits both inhibitory and excitatory actions. Except for the action of $N$ methylglycine, all the inhibitory effects are antagonized by both picrotoxin and strychnine. The effect of $N$-methylglycine is antagonized by strychnine but not picrotoxin.

\section{Methods}

\section{Recording of extracellular action potentials}

The preparation of guinea-pig cerebellar cortex slices and the methods used for superfusion and for the recording of action potentials (spikes) have been described in detail previously (Okamoto \& Quastel, $1973 ;$ 1976). Briefly, after the guinea-pig was killed by stunning, the slice $(0.5 \mathrm{~mm}$ thick) was prepared from the superior vermis by cutting the isolated cerebellum parallel to its uppermost surface. The slice was then promptly placed on a nylon mesh in the superfusion chamber. All solutions, including the control solution and those containing substances to be tested, were applied to the slice by superfusion (flow rate $\simeq 1$ $\mathrm{ml} / \mathrm{min}$ ) through a glass capillary tip (internal diameter $\simeq 0.3 \mathrm{~mm}$ ) placed just above the surface of the slice and close to the recording glass microelectrode (1-2 M $\Omega$ ), filled with $2.5 \mathrm{M} \mathrm{NaCl}$. The control solution $(\mathrm{pH}=7.4)$ consisted of $(\mathrm{mM}): \mathrm{NaCl}$ $125, \mathrm{KCl} 5, \mathrm{CaCl}_{2} 2, \mathrm{MgCl}_{2} 1, \mathrm{NaH}_{2} \mathrm{PO}_{4} 1, \mathrm{NaHCO}_{3}$ 24 and glucose 11 . Amino acids, their sodium salts, or antagonists to be tested for their activities, were dissolved in this solution, the final pH not being affected. The solution was always bubbled with $95 \%$ $\mathrm{O}_{2}$ and $5 \% \mathrm{CO}_{2}$ in the reservoirs and warmed to $37^{\circ} \mathrm{C}$ by a water jacket placed near the superfusion tip. Discharge frequencies of extracellular action potentials (spikes/s) were recorded on an oscillographic recorder Model 7402A (Hewlett Packard) and also printed on a Model 2010A printer (John Fluke) after passing through a frequency counter (Digital counter-timer, Model 1952A, John Fluke). In the dose-response curves the spike discharge rates (spikes/s) were obtained by averaging 5 or more values from cells whose discharge rate remained stable for $20 \mathrm{~s}$ or more. Amino acid and convulsant-free solutions were applied between the applications of solutions containing amino acid or convulsants to avoid possible desensitiziation due to prolonged exposure of the slice to these agents.

\section{Kinetic analyses}

Kinetic analyses of the dose-response relations were carried out in a similar manner to that described in detail in our previous paper (Okamoto \& Quastel, 1976). In short, the theoretical dose-response curve, in the absence of an antagonist, was derived from equation (1).

$$
p=p_{\max } /\left\{1+(\mathrm{K} /[\mathrm{A}])^{n}\right\}
$$

where $p$ is the percentage inhibition of spike discharge frequency by the amino acid, $K$ is the concentration of the amino acid (A) giving $50 \%$ of the maximum response $\left(p_{\max }\right)$ which is 100 , and $n$ is the estimate of the number of molecules of amino acid combining with the receptor site. Values of $\mathrm{K}$ and $\boldsymbol{n}$ for each of the dose-response curves were determined from equation (1A), derived from equation (1).

$$
\mathrm{K}=[\mathrm{A}]\left\{\left(p_{\max } / p\right)-1\right\}^{1 / n}
$$

The observed values of $p$ at various concentrations of A should give a constant value of $K$ at a particular value of $n$ according to equation (1A). This value of $n$ was determined by finding a value, using steps of 0.1 within the range of 0.5 and 4.0 , that resulted in constancy of the value of $K$ at different concentrations of A (Okamoto \& Quastel, 1976). Values of $\boldsymbol{n}$ and K thus determined agreed with the values obtained by Hill plots, $\log _{e}\left[p /\left(p_{\max }-p\right)\right] v s \log _{e}[A]$.

It was expected that values of $n$, thus estimated by equation (1A) would be smaller than the real values, when the $n$-value was not unity, because equation (1) was based on the assumption that concentrations of the intermediates of the sequential reactions between 
the amino acid, $A$, and the receptor, $R$, such as $A R, \ldots A_{n-1} R$ were negligible compared with those of $\mathrm{R}$ and $\mathrm{A}_{n} \mathrm{R}$ (see Okamoto \& Quastel, 1976).

When a competitive antagonist, I, was present, equation (2) or (3) was applied.

$$
\begin{gathered}
p^{\prime}=p_{\max } /\left\{1+(\mathrm{K} /[\mathrm{A}])^{n}\left[1+\left([\mathrm{I}] / \mathrm{K}_{\mathrm{I}}\right)^{m}\right]\right\} \\
=p_{\max } /\left\{1+\left(\mathrm{K}^{\prime} /[\mathrm{A}]\right)^{n}\right\}
\end{gathered}
$$

where $p^{\prime}$ is the percentage inhibition of spike discharge frequency in the presence of the antagonist, where $K^{\prime}$, the concentration of $\mathrm{A}$ to give $50 \%$ of $p_{\max }$, is equal to $\left.\mathrm{K} \mid 1+\left(|\mathrm{I}| / \mathrm{K}_{\mathrm{I}}\right)^{m}\right]^{1 / n}$, and where $\mathrm{K}_{\mathrm{I}}$ is the apparent dissociation constant of the antagonist-receptor complex. The value of $m$ represents the estimate of the number of antagonist molecules combining with the receptor. The value of $m$ was estimated by equation (4).

$$
\left.\log _{\mathrm{e}} \mid\left(p-p^{\prime}\right) / p^{\prime}\right]=\mathrm{m} \cdot \log _{\mathrm{e}}\left([\mathrm{I}] / \mathrm{K}_{\mathrm{I}}\right)-\log _{\mathrm{e}}\left[p_{\max } /\left(p_{\max }-p\right)\right]
$$

The slope of the plot of $\log _{\mathrm{e}}\left[\left(p-p^{\prime}\right) / p^{\prime}\right]$ against $\log _{\mathrm{e}}[\mathrm{I}]$ is equal to $m$, with constant [A] (Okamoto \& Quastel, 1976). The value of $m$ thus estimated, however, should be smaller than the real value when $m$-value is not unity, because equation (2) or (3) was based on the assumption that concentrations of intermediates of the sequential reactions between the antagonist, $I$, and the receptor, $R$, such as $I R, \ldots I_{m-1} R$ were negligible compared with $[R]$ and $\left[I_{m} R\right]$ (see Okamoto \& Quastel, 1976).

The values of $K_{1}$ were estimated, in view of these considerations, using the nearest higher integers to the values of $n$ and $m$ obtained from equations (1A) and (4) respectively, by means of the equal-response method (Gaddum, 1943; Hubbard, Llinás \& Quastel, 1969) using equation (5) which is derived from equation (1) and (2) when $p=p^{\prime}$.

$$
K_{I}=[I] /\left\{\left(\left[A_{1}\right] /\left[A_{2}\right]\right)^{n}-1\right\}^{1 / m}
$$

where $\left[A_{1}\right]$ and $\left[A_{2}\right]$ are the concentrations of $A$ giving equal response in the presence and absence of the antagonist respectively.

\section{Materials}

$N$-methyl- $\gamma$-aminobutyric acid hydrochloride and Dglutamic acid were obtained from Calbiochem., La Jolla, Calif. $N$-methylglycine hydrochloride (Sarcosine), $N$-methylDL-glutamic acid and picrotoxin were purchased from Sigma Chemical, St. Louis, Mo. $N$-methyl $\beta$-alanine was kindly given to us by $\mathrm{Dr}$ G.A.R. Johnston, The Australian National University, Canberra. Strychnine sulphate was purchased from Mallinckrodt Chemical, St. Louis, Mo.

The $N$-methylamino acids used were analysed, preparatory to use, by an amino acid analyzer, for contamination with non-methylated parent amino acids. No such contaminants were detected.

Guinea-pigs, male, adult, 350-400 g, were supplied by the Animal Unit, University of British Columbia, Vancouver, B.C., Canada.

\section{Results}

Effects of $\mathrm{N}$-methylamino acids on spontaneous spike discharge frequencies in cerebellar slices

$N$-methyl- $\gamma$-aminobutyrate $(N$-methylGABA $), \quad N$ methylglycine, $N$-methyltaurine and $N$-methyl $\beta$ alanine each diminished the frequency of spontaneous spike discharges in guinea-pig cerebellar slices in a manner similar to that observed with the corresponding non-methylated amino acid (Okamoto \& Quastel, 1976). Examples of such inhibitory effects are shown in Figure 1. An early excitation often preceded the inhibition and partial recovery often occurred whilst the amino acid was still present. On removal of the amino acid a transient excitation often preceded the recovery. $N$-methyltaurine, however, seemed to be the exception in that full recovery (Figure 1) rarely occurred.

The time-course of these effects of the $N$ methylamino acids also resembled those of the parent amino acids. For example, the rapid onset of the inhibition due to $N$-methylGABA or $N$-methyl $\beta$ alanine was similar to that due to GABA or to $\beta$ alanine respectively. The slow onset of the inhibition due to $N$-methyltaurine resembled that due to taurine (Figure 1; Okamoto \& Quastel, 1976). The brief inhibition due to $N$-methylglycine followed by full recovery of the discharge rate to the initial value was similar to that observed in the presence of glycine.

The inhibitory effects of the $N$-methylamino acids were observed with all cells tested and were reversible. They were quantitatively related to the concentrations of $N$-methylamino acids in the perfusion medium.

\section{Effects of picrotoxin and strychnine on the inhibitory effects of $\mathrm{N}$-methylamino acids}

The inhibitory activity of $N$-methylGABA, $N$ methyltaurine or $N$-methyl $\beta$-alanine was abolished by both picrotoxin and strychnine $(1-50 \mu \mathrm{M})$ in all cells tested. The effect of either convulsant was reversible. The action of $N$-methylglycine was antagonized by strychnine $(0.2-1 \mu \mathrm{M})$ but not by picrotoxin. Examples of these antagonisms by picrotoxin are shown in Figure 1. Similar antagonisms were exhibited by strychnine. The poor specificity of the convulsants on the $N$-methylamino acids is in contrast to their specific effects on the parent, non-methylated, amino acids. For example, the inhibitory action of GABA was abolished by picrotoxin but not by strychnine 


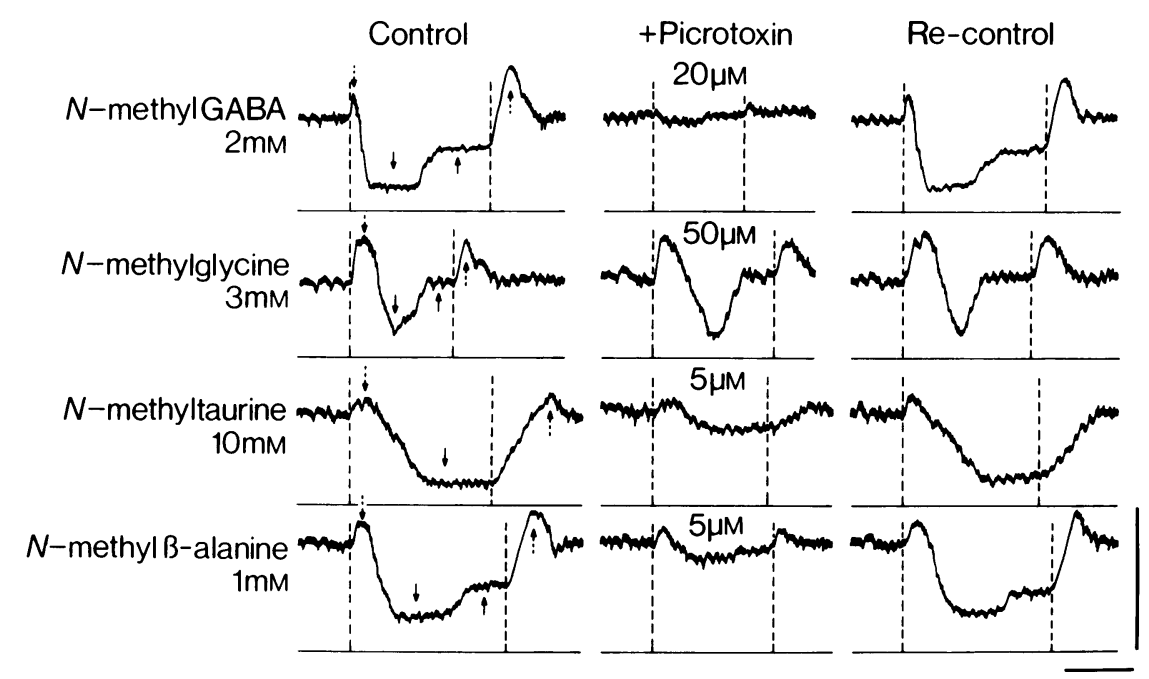

Figure 1 Typical effects of inhibitory $N$-methylamino acids on spontaneous spike discharge frequencies in guinea-pig cerebellar slices. The antagonistic action of picrotoxin.

Records were obtained from four different cells, one cell being used for each of the $N$-methylamino acids. These were applied, at concentrations shown, for a period given by the interval between the two vertical broken lines. Picrotoxin was applied about $30 \mathrm{~s}$ before the application of the $N$-methylamino acid and its effects were shown in the middle records. The left and right records are for the control and re-control (picrotoxin-free) conditions respectively. The latter was recorded about $3 \mathrm{~min}$ after the removal of picrotoxin. Scales: vertical $=100$ spikes $/ \mathrm{s}$; horizontal $=20 \mathrm{~s}$. The solid downward arrows indicate the largest inhibitions, produced by the $\mathrm{N}$-methylamino acids, with which the dose-response plots (Figures $2-5$ ) were obtained. The solid upward arrows indicate the partially recovered spike frequencies in the presence of the $N$-methylamino acids. The broken downward arrows and the broken upward arrows indicate the early excitations by the $\mathrm{N}$ methylamino acids and the after-excitations on removal of the $\mathrm{N}$-methylamino acids respectively. The effects of strychnine (5-50 $\mu \mathrm{M}$ ) (not shown) were similar to those of picrotoxin (see Figures 2-5) except for its selective effect on the action of $N$-methylglycine (Figure 3 ).

whereas that of glycine, taurine or $\beta$-alanine was abolished by strychnine but not by picrotoxin (Okamoto \& Quastel, 1976).

\section{Dose-response curves of the $\mathrm{N}$-methylamino acids}

The effects of $N$-methylGABA, $N$-methylglycine, $N$ methyltaurine and $N$-methyl $\beta$-alanine at different concentrations in the absence or presence of picrotoxin or strychnine are shown in Figures 2-5 where the largest inhibition (as denoted by downward solid arrows in Figure 1) values are recorded. Inhibitions calculated from the partial recoveries given by $N$-methylGABA and $N$-methyl $\beta$-alanine were similar to those given in Figures 2 and 5.

Theoretical log dose-response curves are also given in Figures 2-5. They are derived from equation (1) or (3) in the Methods section. The values of the kinetic constants $\mathrm{K}$ and $n$ (equation 1 ) and $\mathrm{K}^{\prime}$ (equation 3 ) estimated from the best fitted log dose-response curves, recorded in Figures 2-5, are listed in Table 1.

Examination of the $\mathrm{K}$-values (Table 1) shows that the inhibitory activities of the $N$-methylamino acids were 2-15 times smaller than those of corresponding non-methylated amino acids. The values of $K$ previously obtained with the non-methylated amino acids were $0.12 \mathrm{mM}$ for GABA, $0.10 \mathrm{mM}$ for glycine, $1.0 \mathrm{mM}$ for taurine and $0.35 \mathrm{mM}$ for $\beta$-alanine (see Table 1; Okamoto \& Quastel, 1976). The values of $n$, however, i.e., the numbers of molecules of $N$ methylamino acid calculated as combining with the receptor site, were similar to those of the corresponding non-methylated amino acid, i.e., $n=3$ for $N$-methylGABA; 2 for $N$-methylglycine, and 3 for $N$ methyltaurine. An exception was $N$-methyl $\beta$-alanine whose $n$ value was calculated to be 3 whereas that for $\beta$-alanine seemed to be 4 (Okamoto \& Quastel, 1976).

Effects of picrotoxin. Picrotoxin $(1-50 \mu \mathrm{M})$ brought about a parallel shift to the right of the dose-response curve due to $N$-methylGABA or $N$-methyl $\beta$-alanine (Figures 2 and 5) indicating an apparent competition (Okamoto \& Quastel, 1976) between the $N$ methylamino acid and the convulsant. 
Low concentrations (e.g., $0.5 \mu \mathrm{M}$ ) of picrotoxin shifted the dose-response curve of $N$-methyltaurine to the right in parallel, but at high picrotoxin concentrations $(>1.0 \mu \mathrm{M})$ there was a departure from parallelism, the curve being flattened (Figure 4). It was, therefore, evident that the action of picrotoxin with $N$-methyltaurine was not wholly competitive, the nature of its antagonism varying with its concentration.

The numbers, $m$, of picrotoxin molecules combining with the receptor site, as definined in equation (2) and recorded in Table 1, were estimated from the plots of $\log _{\mathrm{e}}\left\{\left(p-p^{\prime}\right) / p^{\prime}\right\}$ against $\log _{\mathrm{e}}[\mathrm{I}]$ (equation 4). These plots, with constant concentrations of $N$ methylGABA, $N$-methyltaurine, and $N$-methyl $\beta$ alanine, were linear and the values of $m$, obtained from the slopes, were 2.2 with $N$-methylGABA, 1.7 with $N$ methyltaurine, and 1.4 with $N$-methyl $\beta$-alanine
(Table 1). However, the value of $m=1.7$ with $N$ methyltaurine, is open to doubt as the effect of picrotoxin with this amino acid was apparently not purely competitive.

It was evident that the value of $m$ considerably exceeded unity with $N$-methylGABA and, therefore, that the number of picrotoxin molecules combining with the $N$-methylGABA receptor site was apparently greater than that combining with the GABA receptor site where $m$ was 1.0 (Okamoto \& Quastel, 1976).

The values of $\mathrm{K}_{\mathrm{I}}$, the apparent dissociation constants of the picrotoxin-receptor complexes, recorded in Table 1, were estimated from the values of the horizontal shifts of the log dose-response curves (Figures 2, 4 and 5) using equation (5).

The value of $\mathrm{K}_{\mathrm{I}}$ for picrotoxin in the presence of $N$ methylGABA $\left(\mathrm{K}_{\mathrm{I}}=2.5 \mu \mathrm{M}\right)$ was smaller than that found with $\mathrm{GABA} \quad\left(\mathrm{K}_{\mathrm{I}}=5.1 \mu \mathrm{M}\right)$ (Okamoto \&

Table 1 Values of kinetic constants estimated for inhibitory actions of $\mathbf{N}$-methylamino acids and for antagonistic effects of convulsants

\begin{tabular}{|c|c|c|c|c|}
\hline & $\begin{array}{c}K \text { or } \\
K^{\prime}(m M)\end{array}$ & $n$ & $\begin{array}{c}K_{1} \\
(\mu M)\end{array}$ & $\mathrm{m}$ \\
\hline $\begin{array}{l}N \text { - } \text { methylGABA } \\
\quad+\text { picrotoxin }(20 \mu \mathrm{M}) \\
\quad+\text { strychnine }(10 \mu \mathrm{M})\end{array}$ & $\begin{array}{l}1.32 \\
4.74 \\
2.62\end{array}$ & $\begin{array}{l}2.4 \\
2.5 \\
2.6\end{array}$ & $\begin{array}{l}\overline{2.52} \\
1.28\end{array}$ & $\begin{array}{l}\overline{2.2} \\
1.1\end{array}$ \\
\hline $\begin{array}{l}N \text { - methylglycine } \\
\quad+\text { strychnine }(0.2 \mu \mathrm{M}) \\
+ \text { strychnine }(0.4 \mu \mathrm{M})\end{array}$ & $\begin{array}{r}1.59 \\
6.00 \\
12.36\end{array}$ & $\begin{array}{l}1.4 \\
1.5 \\
0.9\end{array}$ & $\overline{0.055}$ & $\overline{1.7}$ \\
\hline $\begin{array}{l}N \text {-methyltaurine } \\
\quad+\text { picrotoxin }(0.5 \mu \mathrm{M}) \\
\quad+\text { picrotoxin }(1 \mu \mathrm{M}) \\
\quad+\text { strychnine }(20 \mu \mathrm{M})\end{array}$ & $\begin{array}{r}5.45 \\
10.40 \\
17.53 \\
18.45\end{array}$ & $\begin{array}{l}2.4 \\
2.0 \\
1.3 \\
2.1\end{array}$ & $\frac{0 . \overline{21}}{0 . \overline{55}}$ & $\frac{\overline{1.7}}{1.0}$ \\
\hline $\begin{array}{l}N \text {-methyl } \beta \text {-alanine } \\
\quad+\text { picrotoxin }(5 \mu \mathrm{M}) \\
\quad+\text { strychnine }(10 \mu \mathrm{M})\end{array}$ & $\begin{array}{l}0.62 \\
2.19 \\
1.10\end{array}$ & $\begin{array}{l}2.7 \\
2.7 \\
2.0\end{array}$ & $\begin{array}{l}\overline{-76} \\
2.18\end{array}$ & $\begin{array}{l}\overline{1.4} \\
1.1\end{array}$ \\
\hline $\begin{array}{c}N \text {-methylDL-glutamate } \\
\quad+\text { picrotoxin }(3 \mu \mathrm{M}) \\
+ \text { strychnine }(5 \mu \mathrm{M})\end{array}$ & $\begin{array}{l}0.45 \\
4.94 \\
1.96\end{array}$ & $\begin{array}{l}1.1 \\
0.9 \\
0.9\end{array}$ & $\begin{array}{l}1 . \overline{12} \\
1.23\end{array}$ & $\begin{array}{l}\overline{1.9} \\
1.1\end{array}$ \\
\hline
\end{tabular}

The values of $K$ and $K^{\prime}$ are concentrations of the $N$-methylamino acids required to give $50 \%$ of the maximum inhibition in the absence and presence of the antagonist respectively (equations 1 and 3 ). The values of $n$, the numbers of molecules of the $N$-methylamino acid combining with the receptor site, calculated from equations 1 and 3, are those that gave the best fits of the theoretical log dose-response curves to the observed values of the percentage inhibitions. The values of $K_{1}$ were estimated from the extents of the parallel shifts, at $50 \%$ inhibition of the log dose-response curves (Figures 2-5). The values of $n$ used for the calculation of $K_{1}$ values (using equation 5 ) were $3,2,3,3$ and 1 for $N$-methylGABA, $N$-methylglycine, $N$-methyltaurine, $N$-methyl $\beta$ alanine and $N$-methylDL-glutamate respectively. These $n$ values are the nearest higher integers to the values of $n$ obtained in the absence of the antagonists. The values of $m$ shown were estimated using equation (4). The values of $m$ used for calculation of $K_{1}$ values were the nearest higher integers to the observed $m$ values. They were 3 for picrotoxin with $N$-methylGABA, 1 for strychnine with $N$-methylGABA; 2 for strychnine with $N$ methylglycine; 2 for picrotoxin with $N$-methyltaurine, 1 for strychnine with $N$-methyltaurine; 2 for picrotoxin with $N$-methyl $\beta$-alanine, 1 for strychnine with $N$-methyl $\beta$-alanine, and 2 for picrotoxin with $N$-methylDLglutamate and 1 for strychnine with $N$-methylDL-glutamate. See Methods section for reasons for employing such whole integers of $n$ and $m$. 


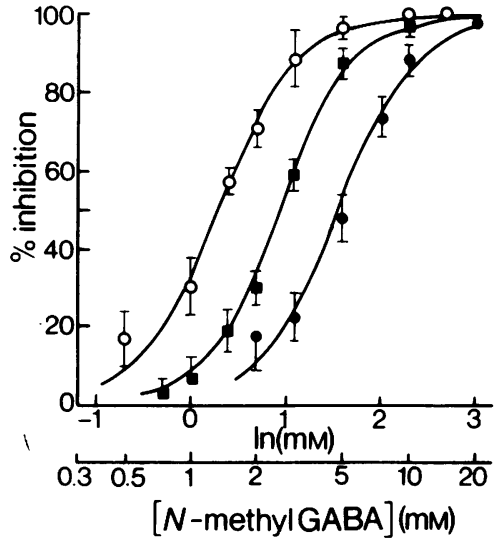

Figure 2 Log dose-response curves of $N$ methyIGABA. Typical effects of picrotoxin and strychnine. Ordinate scale = percentage inhibition of spike discharge frequency by $N$-methylGABA. Abscissa scale $=\log _{e}$ concentration $(\mathrm{mM})$ of $N$ methyIGABA. The values plotted were obtained from the largest inhibitions, as denoted by solid downward arrows in Figure 1. They are the means of values found with 5-14 cells in several slices. Vertical lines show s.e. means. (O) Control; (O) with $20 \mu \mathrm{M}$ picrotoxin; ( $\square$ ) with $10 \mu \mathrm{M}$ strychnine. Lower concentrations (down to $1 \mu \mathrm{M}$ ) of both of the convulsants were also tested. They gave similar but smaller parallel shifts. The lines are theoretical curves (equation 1 or 3 ) that gave the best fits to the observed values. Values of $n, K$ and $K^{\prime}$ are given in Table 1.

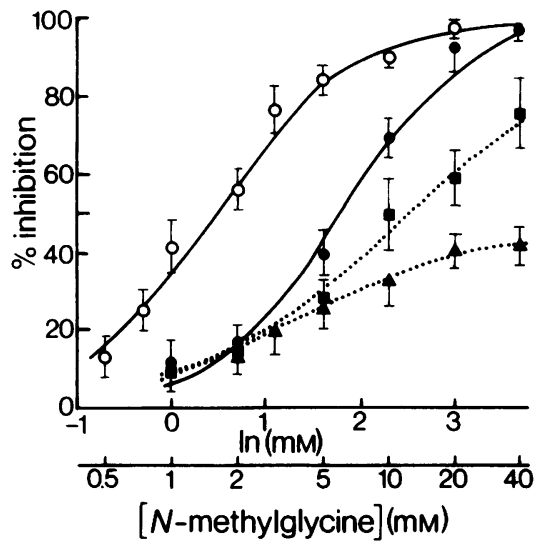

Figure 3 Log dose-response curves for $N$ methylglycine. Typical effects of strychnine. Ordinate scale = percentage inhibition of spike discharge frequency by $N$-methylglycine. Abscissa scale $=\log _{e}$ concentrations (mM) of $N$-methylglycine. The values plotted were obtained from the largest inhibitions (Figure 1, solid downward arrows). They are the means of values found with 5-12 cells in several slices. Vertical lines show s.e. means. (O) Control; (O) with $0.2 \mu \mathrm{M}$ strychnine; $(\square)$ with $0.4 \mu \mathrm{M}$ strychnine; (A) with $1 \mu \mathrm{M}$ strychnine. The solid lines are theoretical curves (equation 1 or 3 ) that gave the best fits to the observed values. The dotted lines are not theoretical curves, they simply connect the observed values. Values of $n, K$ or $K^{\prime}$ are given in Table 1. Picrotoxin $(1-50 \mu \mathrm{M})$ was without effect on the inhibitions by $N$-methylglycine.
Quastel, 1976). Judging from the $K_{I}$ values (Table 1), picrotoxin blocked the actions of $N$-methyltaurine and $N$-methyl $\beta$-alanine more effectively than those of $N$ methylGABA or GABA.

Effects of strychnine. Strychnine (1-50 $\mu \mathrm{M})$ abolished the inhibitory effects of all the $N$ methylamino acids tested in all cells examined. Its action was reversible.

The presence of this convulsant caused a parallel shift to the right of the log dose-response curves of $N$ methylGABA, $N$-methyltaurine and $N$-methyl $\beta$ alanine (Figures 2, 4 and 5).

The log dose-response curve of $N$-methylglycine was shifted to the right in a parallel manner when the strychnine concentration was $0.2 \mu \mathrm{M}$ (Figure 3). At higher concentrations $(0.4 \mu \mathrm{M}$ and $1 \mu \mathrm{M})$ of strychnine the curves departed from parallelism and became flatter (Figure 3). It seemed, therefore, that the strychnine antagonisms of $N$-methylGABA, $N$ methyltaurine and $N$-methyl $\beta$-alanine were competitive, whilst that of $N$-methylglycine was not competitive at relatively high strychnine concentrations.

The $m$ values for strychnine (Table 1), estimated from equation (4), were 1.1 with $N$-methylGABA or $N$-methyl $\beta$-alanine, 1.0 with $N$-methyltaurine and 1.7 with $N$-methylglycine. The numbers, therefore, of strychnine molecules combining with the receptor site(s) to abolish the inhibitory actions of the $N$ methylamino acids, seemed to be 1 with the exception of $N$-methylglycine, whose $m$-value, as with that for picrotoxin and $N$-methyltaurine, is open to doubt.

The $m$ value for strychnine with glycine, taurine or $\beta$-alanine has been previously estimated as 1 (Okamoto \& Quastel, 1976).

The $K_{I}$ values (dissociation constant) for strychnine (estimated similarly to those for picrotoxin) are given in Table 1. A comparison of these values with those found in presence of glycine $\left(\mathrm{K}_{\mathrm{I}}=0.25 \mu \mathrm{M}\right)$, taurine $\left(\mathrm{K}_{\mathrm{I}}=0.35 \mu \mathrm{M}\right)$ or $\beta$-alanine $\left(\mathrm{K}_{\mathrm{I}}=0.48 \mu \mathrm{M}\right)$ (Okamoto \& Quastel, 1976) shows that strychnine was as effective on $N$-methyltaurine as on taurine, less effective on $N$-methyl $\beta$-alanine than on $\beta$-alanine and 


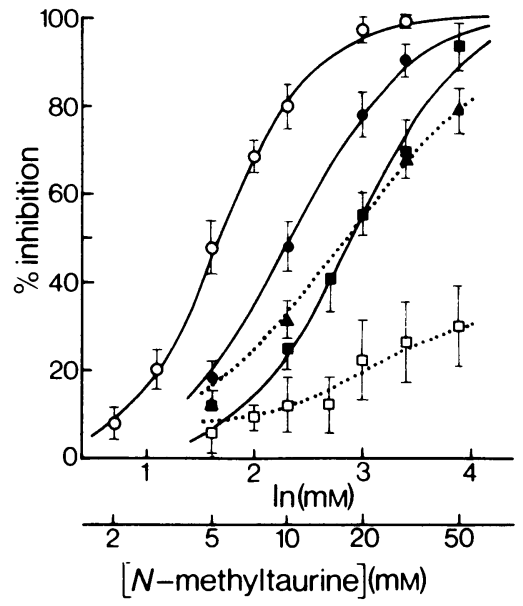

Figure 4 Log dose-response curves for $N$ methyltaurine. The effects of picrotoxin and strychnine. Ordinate scale $=$ percentage inhibition of spike discharge frequency by $N$-methyltaurine. Abscissa scale $=\log _{e}$ concentration $(\mathrm{mM})$ of $N$ methyltaurine. The values plotted were obtained from the largest inhibitions (Figure 1, solid downward arrows). They are the means of values found with 6-21 cells in several slices. Vertical lines show s.e. means. (O) Control; (O) with $0.5 \mu \mathrm{M}$ picrotoxin; (A) with $1 \mu \mathrm{M}$ picrotoxin; ( $\square$ ) with $5 \mu \mathrm{M}$ picrotoxin; ( $\square$ ) with $20 \mu \mathrm{M}$ strychnine. Lower concentrations (down to $1 \mu \mathrm{M}$ ) of strychnine were also tested. They gave similar but smaller parallel shifts. The solid lines are theoretical curves (equation 1 or 3 ) that gave the best fits to the observed values. The dotted lines are not theoretical curves; they simply connect the observed values. Values of $n, \mathrm{~K}$ or $\mathrm{K}^{\prime}$ are given in Table 1.

probably more effective on $\mathrm{N}$-methylglycine than on glycine.

Effects of $\mathrm{N}$-methylDL-glutamate and $L$ - or $D$ glutamate on spontaneous spike discharge frequencies

Action of N-methylDL-glutamate. Application of $N$ methylDL-glutamate resulted in a consistent biphasic action in all (54) cells investigated. There was always a prompt initial inhibition followed by a strong excitation (Figure 6). The inhibitory and excitatory activities of this amino acid were reversible and they increased according to the concentration. A small early excitation (Figure 6) often preceded the inhibition. With 2 cells out of 54 cells examined the strong excitation preceded the inhibition. At relatively low concentrations $(<0.5 \mathrm{~mm})$ of $N$-methylDLglutamate its action was predominantly inhibitory.

Action of L- or D-glutamate. Application of Lglutamate occasionally brought about a biphasic action similar to that given by $N$-methylDL-glutamate.

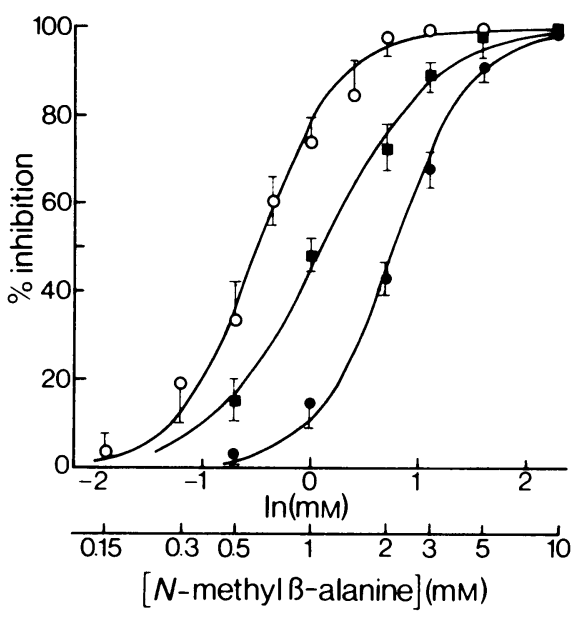

Figure 5 Log dose-response curves for $N$-methyl $\beta$ alanine. The effects of picrotoxin and strychnine. Ordinate scale $=$ percentage inhibition of spike discharge frequency by $N$-methyl $\beta$-alanine. Abscissa scale $=\log _{e}$ concentration (mM) of $N$-methyl $\beta$ alanine. The values plotted were obtained from the largest inhibitions (Figure 1, solid downward arrows). They are the means of values found with $8-15$ cells in several slices. Vertical lines show s.e. means. (O) Control; (O) with $5 \mu \mathrm{M}$ picrotoxin; (口) with $10 \mu \mathrm{M}$ strychnine. Strychnine or picrotoxin $(1-50 \mu \mathrm{M})$ gave similar parallel shifts but they varied in extent according to the concentrations. The lines are theoretical curves (equation 1 or 3 ) that gave the best fits to the observed values. Values of $n, K$ or $K^{\prime}$ are given in Table 1.

Typical results are shown in Figure 6. Such biphasic action was only observed on about 8 of more than 100 cells examined.

D-Glutamate behaved in a manner similar to that of L-glutamate, but its potency (inhibitory and excitatory) was much weaker than that of L-glutamate (results not shown).

Effects of convulsants on the inhibitory activity of $\mathrm{N}$ methylDL-glutamate

Whereas the occasional inhibitory effects of $\mathrm{L}$ - and $\mathrm{D}$ glutamates were abolished by picrotoxin $(5-50 \mu \mathrm{M})$ and not by strychnine $(5-50 \mu \mathrm{M})$, the persistent effects of $N$-methylDL-glutamate were antagonized by both picrotoxin $(1-50 \mu \mathrm{M})$ and strychnine $(1-50 \mu \mathrm{M})$ (Figure 6). The abolition of the inhibitions by the convulsants resulted in an earlier onset of the excitation whose magnitude was unaffected (Figure 6). The block of the inhibitions by the convulsants was always reversible with $N$-methylDL-glutamate but not 


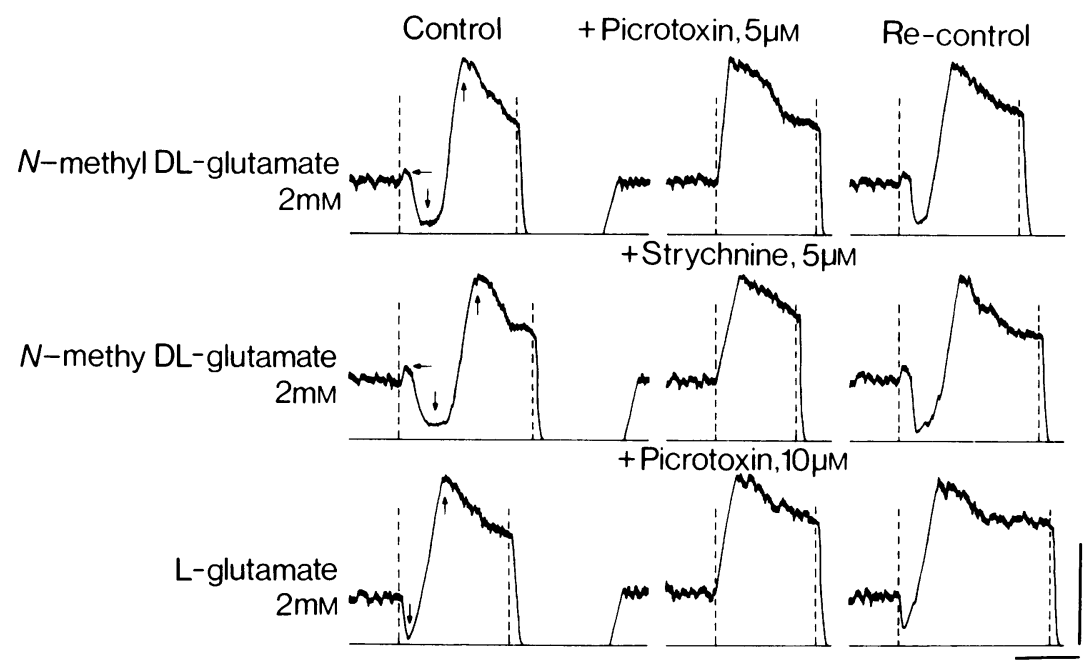

Figure 6 Typical effects of $N$-methylDL-glutamate and of L-glutamate on spike discharge frequencies. The antagonistic actions of picrotoxin and strychnine. Records were obtained from three different cells, one cell being used for each set of results. $\mathrm{N}$-methylDL-glutamate or L-glutamate was applied, at the concentrations shown, for a period given by the interval between the two vertical broken lines. Picrotoxin or strychnine was applied about 30 s before the application of the $N$-methylDL-glutamate or L-glutamate. Their effects are shown in the middle records. The left and right records are for the control and re-control (the convulsant-free) conditions respectively. The latter was recorded about $5 \mathrm{~min}$ after the removal of the convulsants. Scales: vertical $=100$ spikes $/ \mathbf{s}$; horizontal $=20$ seconds. The downward arrows and upward arrows indicate respectively the inhibition and excitation by $N$-methylDL-glutamate or L-glutamate. Horizontal arrows indicate the early excitations. D-Glutamate, not shown, gave inhibitory and excitatory effects similar to those of Lglutamate. Its inhibitory effect was blocked by picrotoxin $(10 \mu \mathrm{M})$. Strychnine at concentrations up to $50 \mu \mathrm{M}$ did not affect the inhibitory action of $L$ - or D-glutamate. Silent periods occurred immediately after the removal of $N$ methyloL-glutamate or L-glutamate. This is demonstrated in the control column.

always so with L- or D-glutamate. Repeated applications of picrotoxin caused the inhibitory action of $\mathrm{L}$ - and $\mathrm{D}$-glutamate to become smaller.

\section{Dose-response curves of inhibitory effect of $\mathrm{N}$ - methylDL-glutamate}

The log dose-response curves of the inhibitory effect of $N$-methylDL-glutamate and of the antagonisms exerted by picrotoxin and strychnine, are shown in Figure 7.

The value of $n$ giving the best fit of the theoretical dose-response curve to the experimental values was 1.1 and the value of $\mathrm{K}$ was estimated to be $0.45 \mathrm{mM}$ (Table 1). It seemed, therefore, that only one molecule of $N$-methylDL-glutamate was necessary to combine with its receptor site to bring about inhibition of frequency of the spike discharges.

The application of picrotoxin $(1-50 \mu \mathrm{M})$ or strychnine $(1-50 \mu \mathrm{M})$ brought about parallel shifts of the $\log$ dose-response curves to the right and the values of $n$ were unchanged $(n=0.9$, Table 1$)$. These results indicated competitive antagonism by these convulsants.
The number of molecules of picrotoxin combining with the receptor site to yield antagonism was estimated to be 1.9 and that for strychnine was estimated to be 1.1 (Table 1). It would seem that two molecules of picrotoxin per receptor site were required for the $N$-methylDL-glutamate antagonism, as shown also for $N$-methylGABA and $N$-methyl $\beta$-alanine (Table 1). Only one molecule of strychnine seemed to be necessary for the antagonism, as shown also for $N$ methylGABA, $N$-methyltaurine and $N$-methyl $\beta$ alanine (Table 1).

The values of $\mathrm{K}_{\mathrm{I}}$ were estimated to be $1.1 \mu \mathrm{M}$ for picrotoxin and $1.2 \mu \mathrm{M}$ for strychnine in the presence of $N$-methylDL-glutamate (Table 1 ).

\section{Discussion}

The present study has demonstrated the inhibitory effects, on the frequencies of spontaneous spike discharges displayed by guinea-pig cerebellar slices, of $N$-methylGABA, $N$-methyltaurine, $N$-methylglycine, $N$-methyl $\beta$-alanine and $N$-methylDL-glutamate as well as the excitatory effect of $N$-methylDL-glutamate. 


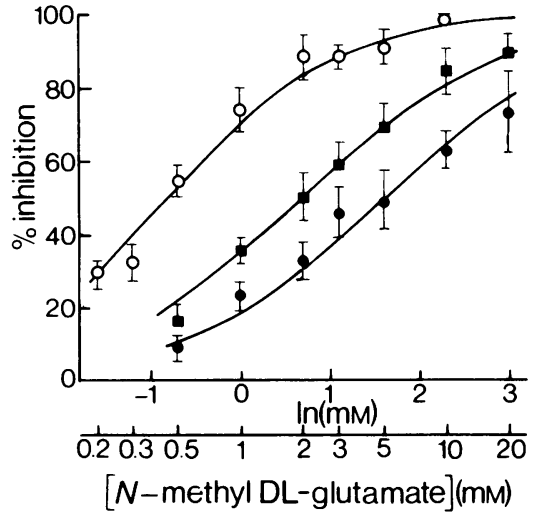

Figure 7 Log dose-response curves for the inhibitory actions of $N$-methylDL-glutamate. The effects of picrotoxin and strychnine. Ordinate scale $=$ percentage inhibitions of spike discharge frequency by $N$-methylDL-glutamate. Abscissa scale $=\log _{e}$ concentration ( $\mathrm{mM}$ ) of $N$-methylDL-glutamate. The values plotted were obtained from the largest inhibitions, as denoted by downward arrows in Figure 6. They are the means of values found with 5-13 cells in several slices. Vertical lines show s.e. means. (O) Control; (O) with $3 \mu \mathrm{M}$ picrotoxin; ( $\square$ ) with $5 \mu \mathrm{M}$ strychnine. Similar parallel but variable shifts of the control curve were observed at concentrations of picrotoxin between 1 and $20 \mu \mathrm{M}$. The lines are theoretical curves (equation 1 or 3 ) that gave the best fits to the observed values. Values of $n, K$ or $K^{\prime}$ are given in Table 1.

These activities of $N$-methylamino acids were not due to the presence in the preparations of these amino acids and in superfusing media, of the non-methylated amino acids for the following reasons: (1) No such contaminating amino acids were detected by amino acid analysis, (2) their inhibitory effects were antagonized by both picrotoxin and strychnine in a manner different from that exerted with the nonmethylated amino acids, (3) kinetic analyses revealed different affinities for their receptor sites from those shown by the corresponding non-methylated amino acids.

It is particularly noteworthy that the inhibitory activities of $N$-methylGABA, $N$-methyltaurine, $N$ methyl $\beta$-alanine and $N$-methylDL-glutamate were antagonized by both picrotoxin and strychnine, a phenomenon distinct from the specific effects in cerebellar slices of picrotoxin on inhibitions due to GABA and of strychnine on those due to glycine, taurine and $\beta$-alanine.

The question at once arose as to whether the $N$ methylamino acids (apart from $N$-methylglycine) are able to combine with both the receptor group selectively specific for picrotoxin and that (or those) specific for strychnine. It would be unlikely, if such combinations occur independently, that one antagonist would bring about almost complete abolition of the inhibitory activity of the $N$ methylamino acid. For example, the inhibitory effects of $N$-methylGABA and $N$-methyl $\beta$-alanine at low concentrations are almost completely abolished by either picrotoxin or strychnine (see lower portions of the dose-response curves in Figures 2 and 5). It is perhaps possible that $N$-methylamino acids must combine with both picrotoxin-sensitive and strychnine-sensitive receptors, before an inhibitory action on the spike frequency can occur. In this case, blockade of either of the receptors by either strychnine or picrotoxin, would abolish the inhibitory activity of the $N$-methylamino acid. Another possibility is the existence of a special type of receptor site, for the $N$-methylamino acids, that is affected by both picrotoxin and strychnine. Presumably a receptor originally sensitive to only one convulsant could become sensitive to the other convulsant after combination with a $\mathrm{N}$-methylamino acid. Clearly further studies are required to distinguish between these and other possible explanations.

The inhibitory activity of $N$-methylglycine is abolished only by strychnine and not by picrotoxin. There is no need, therefore, to consider, a combined picrotoxin- and strychnine-sensitive receptor site.

The parallel shifts of the log dose-response curves of $N$-methylGABA, ' $N$-methyl $\beta$-alanine and $N$-methylDLglutamate brought about by the convulsants show the antagonism to be of a competitive nature (Okamoto \& Quastel, 1976). High concentrations (such as $50 \mu \mathrm{M}$ ) of the convulsants were not tested because of the possible occurrence of non-specific actions of the convulsants at such high concentrations (Freeman, 1973).

The antagonism by strychnine of the action of $N$ methylglycine, however, appeared to be competitive only at the low concentration $(0.2 \mu \mathrm{M})$ of strychnine. At higher concentrations $(0.4$ or $1 \mu \mathrm{M})$ it was not competitive (Figure 3). $\mathrm{N}$-methyltaurine also seems to be antagonized competitively by only a low concentration (e.g. $0.5 \mu \mathrm{M}$ ) of picrotoxin (Figure 4).

\section{Biphasic action of $\mathrm{N}$-methylDL-glutamate}

Inhibitory effects. As the occasional initial inhibitory effects of both L- and D-glutamate (Figure 6) on the spike discharges were blocked by picrotoxin and not by strychnine (Figure 6), the release of endogenous GABA, or closely related substances, from nerve terminals of interneurones such as the basket or stellate cells that are tonically inhibitory to the Purkinje cells, might be responsible for the initial inhibitory effects. This, however, is not the explanation of the inhibitory action of $N$-methylDL-glutamate, because the action is antagonized by both picrotoxin and strychnine (Figures 6 and 7). 
Excitatory effects. The excitatory action of $N$ methylDL-glutamate resembled that of $\mathrm{L}$ - or $\mathrm{D}$ glutamate. However, the maximum increases of excitation achieved by these amino acids were $600 \%$ by L-glutamate, $900 \%$ by $N$-methylDL-glutamate and
$450 \%$ by D-glutamate. Neither picrotoxin nor strychnine affected the excitation.

We gratefully acknowledge financial assistance of the Medical Research Council of Canada.

\section{References}

BOARDER, M.R., OON, M.C.H. \& RODNIGHT, R. (1976). Mass spectrometric identification of $\mathrm{N}$-monomethyl tryptamine following incubation of tryptamine with brain protein and S-adenosyl methionine or 5-methyl tetrahydrofolic acid. Biochem. Pharmac., 25, 2109-2112.

CURTIS, D.R., PHILlIS, J.W. \& WATKINS, J.C. (1961). Actions of amino acids on the isolated hemisected spinal cord of the toad. Br. J. Pharmac. Chemother., 16, $262-283$.

CURTIS, D.R. \& WATKINS, J.C. (1960). The excitation and depression of spinal neurons by structurally related amino acids. J. Neurochem., 6, 117-141.

CURTIS, D.R. \& WATKINS, J.C. (1963). Acidic amino acids with strong excitatory actions on mammalian neurons. $J$. Physiol., Lond., 166, 1-14.

FREEMAN, A.R. (1973). Electrophysiological analysis of the actions of strychnine, bicuculline and picrotoxin on the axonal membrane. J. Neurobiol., 4, 567-582.

GADDUM, J.H. (1943). Biological aspects of drug action. The antagonism of drugs. Trans. Faraday Soc., 39, $323-332$.
GugGenheim, M. (1951). Die Biogenen Amine p. 239. Basel: Verlag von S. Karger, N.Y.

HUBBARD, J.I., LLINÁS, R. \& QUASTEL, D.M.J. (1969). Electrophysiological Analysis of Synaptic Transmission pp. 185-188. London: Arnold.

JOHNSTON, G.A.R. \& STEPHANSON, A.L. (1976). Inhibitors of the glial uptake of $\beta$-alanine in rat brain slices. Brain Res., 102, 374-378.

OKAMOTO, K. \& QUASTEL, J.H. (1973). Spontaneous action potentials in isolated guinea-pig cerebellar slices: effects of amino acids and conditions affecting sodium and water uptake. Proc. Roy. Soc., B, 184, 83-90.

OKAMOTO, K. \& QUASTEL, J.H. (1976). Effects of amino acids and convulsants on spontaneous action potentials in cerebellar cortex slices. Br.J. Pharmac., 57, 3-15.

SCOTT, C.R. \& LABBE, R.F. (1974). Disorders in glycine and sarcosine metabolism. Metab. Endocr. Genet. Disord. Child., 2, 819-827.

(Received June 16, 1976. Revised November 1, 1976.) 